\title{
Effect of maternal education and ethnic background on infant development
}

\author{
TERESA IVANANS \\ From the Department of Social Medicine, Hadassah Medical School, Hebrew University, Jerusalem, \\ Israel
}

\begin{abstract}
Ivanans, T. (1975). Archives of Disease in Childhood, 50, 454 . Effect of maternal education and ethnic background on infant development. We examined the influence of maternal education and ethnic background on the four main areas of development (as measured by the Brunet-Lezine adaptation of Gesell's developmental schedule) of their infants. 173 babies were examined at the ages of 3,6,9, and 12 months in the Kiryat Yovel area of Jerusalem, an area where Jews from North Africa, Asia, Europe, and Israel are represented at different educational levels but all share the same maternal and child care services. The mean development quotients (DQs) of the infants of highly educated mothers were higher in all four areas of development than those of infants whose mothers were of low education. Further, North African infants of middle educated mothers had higher DQs than those of middle education European mothers, especially in motor and adaptive areas. It was concluded from this study that higher education of mothers will be expressed in higher DQs of their babies. This was true in all ethnic groups. However, where educational groups were comparable, North African babies have shown better development than all other groups, while European babies were the least developed.
\end{abstract}

Developmental tests and the taking of a developmental history have become an integral part of the examination of the child. Nonetheless, the actual meaning and use of these tests is still controversial. As early as 1877 it was recognized by Charles Darwin that the development of a child is an orderly process. His first work on this was on his first child in 1851. From the study of this orderliness of development, Gesell and Amatruda (1947) hypothesized, 'where there is lawfulness, there is potential for prediction', but cautioned that this prediction is affected by many variables affecting the child's development. Broadly stated the two main variables are genetic and environmental and it is around this problem that most controversy has centred. The genetic constitution of a child is fixed but environment is variable in one or more directions. There may therefore be scope for intervention in certain aspects of the environment.

Israel, with its many well-defined ethnic groups, provides an especially rich opportunity to evaluate the

Received 21 October 1974. development of children in relation to both genetic and environmental aspects. One of the most important features is that in Israeli society there is no segregation of ethnic groups in terms of services rendered to the child. In the particular group studied, furthermore, all subjects received services from the same community health centre.

The purpose of this study was to test the developmental quotient (DQ) of infants under the age of one year in the four main areas of development, as influenced by the interaction of ethnic group and the parents' socioeconomic background (measured by mother's level of education) when geographic neighbourhood and child health services are equal.

\section{Material and methods}

A study was performed between 10 August 1971 and 1 November 1971 in the Kiryat Yovel area of Jerusalem, a suburb of Jerusalem located on the western side of the city. The maternal and child health services of this area are served by a community health centre. In the geographic area served by these clinics are to be found families representing the four main ethnic groups, i.e. North African, European, Asian, and Israeli. 


\section{Effect of maternal education and ethnic background on infant development}

Notification of all births in this area is sent to the clinics by the Ministry of Health and the mother is visited by a public health nurse. Further appointments are made for the child to be seen at 3-month intervals. The child is given both a general and developmental examination at each visit to the clinic. For the purpose of the study, all the infants who came to the clinic were given a developmental examination by either the author or another doctor. Interexaminer reliability was achieved by the two examiners working together and a consensus was reached as to whether a child should be scored as having performed the item and also as to the quality of performance of the test item. The infant was examined sitting on the mother's lap next to a table or on a couch for the appropriate item. Criteria for excluding children from the study population were: (1) Birthweight of $<2500 \mathrm{~g}$. (2) Diagnosis of brain damage havi-g been made by either the hospital or another physician. (3) Presence of gross physical abnormalities: congenital or acquired, e.g. heart disease. (4) Metabolic or genetic abnormalities. During the study, therefore, 3 children were excluded for deafness, congenital heart disease, and birthweight of $<2500 \mathrm{~g}$.

The age limits for examination were assigned as 3 months \pm 2 weeks, 6 months \pm 2 weeks, 9 months \pm 4 weeks, and 12 months \pm 6 weeks. A larger age difference was used in the older groups because changes in development occur at a slower rate.

The system of examination chosen was the Brunet and Lezine (1951) adaptation of Gesell's developmental schedule. The test consists of 10 items in each group -four of them questions to the mother concerning the child's abilities. In addition, some of these items could also be observed by the examiner in confirmation of the mother's statement. All the language items for this age group were in the questionnaire section. This also applied to sociopersonal aspects except for three items - one at 3 months, one at 5 months, and one at 7 months, all of which were components of the examination.

The primary objective was to present the test items in a systematic manner, though this was often modified in accordance with the child's convenience and reactions to the examination situation. The child was scored on a system of a base and ceiling. Items appropriate for his age were presented and if he could not perform them appropriately as stated in the test, then he was presented with items of earlier ages until he could complete all items in the section. If he completed all the items in the age-appropriate section, the next section was taken until the child could no longer perform items, i.e. the ceiling. From this his DQ was calculated and the ratio of developmental to actual age was calculated in the four areas of development, motor, adaptive, language, and social (significance of difference between the various groups was calculated using Student's ' $t$ ' test). Information regarding the following variables was obtained from the files and categorized.

(1) Sex of child.

(2) Age of child-calculated from date of birth and grouped into four categories of $3,6,9$, and 12 months.

(3) Birth rank of child, defined as the number of live births, categories being $1,2,3$, and 4 , and above.

(4) Age of mother in years, calculated from year of birth and categorized (a) 20 years and less, (b) 21-24 years, (c) 25-29 years, (d) 30 years and above.

(5) Country of birth of mother in the following groups, (a) North Africa, (b) Israel, (c) Asia, (d) Europe, N. and S. America, S. Africa.

(6) Years of schooling of mother as stated in the file and grouped (a) low education level 0-8 years, (b) medium educational level 9-12 years, (c) high educational level above 12 years.

From the total population of $\mathbf{4 1 2}$ babies registered at the clinic for the appropriate age, 173 babies were examined. The group studied did not differ from the rest of the population with regard to sex, age grouping, and years of schooling of the mother, but differed in birth rank, country of origin of the mother, and age of mother.

\section{Results}

The distribution of total DQs of the 173 babies was normal. With increasing education of the mother, the mean developmental scores were higher, and this was true for all developmental areas (Table I). A significant influence of mother's level (or category) of education on the child's DQ could be identified (Table II). It should be noted, however, that the motor area appeared to be least affected by education in comparison to adaptive, language, and social areas.

\section{TABLE I}

Means and SDs of developmental areas by educational level of mother.

\begin{tabular}{|c|c|c|c|c|c|c|c|c|c|}
\hline \multirow{3}{*}{ Education (years) } & \multirow{3}{*}{ No. } & \multicolumn{8}{|c|}{ Developmental DQs } \\
\hline & & \multicolumn{2}{|c|}{ Motor } & \multicolumn{2}{|c|}{ Adaptive } & \multicolumn{2}{|c|}{ Language } & \multicolumn{2}{|c|}{ Social } \\
\hline & & Mean DQ & SD & Mean DQ & SD & Mean DQ & SD & Mean DQ & SD \\
\hline $\begin{array}{l}\text { Low 0-8 } \\
\text { Medium 9-12 } \\
\text { High > 12 }\end{array}$ & $\begin{array}{l}60 \\
72 \\
41\end{array}$ & $\begin{array}{l}101 \cdot 2 \\
105 \cdot 3 \\
107 \cdot 5\end{array}$ & $\begin{array}{l}13 \cdot 3 \\
14 \cdot 2 \\
12 \cdot 7\end{array}$ & $\begin{array}{r}97 \cdot 8 \\
101 \cdot 4 \\
107 \cdot 4\end{array}$ & $\begin{array}{l}12 \cdot 8 \\
11 \cdot 6 \\
12 \cdot 6\end{array}$ & $\begin{array}{l}105 \cdot 6 \\
107 \cdot 9 \\
114 \cdot 7\end{array}$ & $\begin{array}{l}15 \cdot 6 \\
13 \cdot 0 \\
14 \cdot 4\end{array}$ & $\begin{array}{l}101 \cdot 9 \\
106 \cdot 2 \\
111 \cdot 9\end{array}$ & $\begin{array}{l}14 \cdot 4 \\
13 \cdot 8 \\
14 \cdot 2\end{array}$ \\
\hline
\end{tabular}


TABLE II

Differences in means of the four developmental areas for babies of mothers of higher and lower educational levels

\begin{tabular}{|c|c|c|c|c|}
\hline & Mean DQ of high education & Mean DQ of low education & Difference & $\mathbf{P}$ \\
\hline $\begin{array}{l}\text { Motor } \\
\text { Adaptive } \\
\text { Language } \\
\text { Social }\end{array}$ & $\begin{array}{l}107 \cdot 5 \\
107 \cdot 4 \\
114 \cdot 7 \\
111 \cdot 9\end{array}$ & $\begin{array}{r}101 \cdot 2 \\
97 \cdot 8 \\
105 \cdot 6 \\
101 \cdot 9\end{array}$ & $\begin{array}{l}6 \cdot 3 \\
9 \cdot 6 \\
9 \cdot 1 \\
9 \cdot 1\end{array}$ & $\begin{array}{l}<0.02 \\
<0.01 \\
<0.02 \\
<0.01\end{array}$ \\
\hline
\end{tabular}

For the purpose of comparison between ethnic groups, only the medium educational group of mothers was used. This was the only one comparable in all four ethnic groups. It was found that in the overall scoring the North African babies attained the highest levels in all developmental areas, while the European babies scored the lowest (Table III). However, when comparing North African to European in each of the developmental areas (Table IV), it was found that only the motor and adaptive areas were significantly different, while no such difference was apparent within language and social areas.

\section{Discussion}

Two main findings emerge from this study. First, the mean DQs of the progeny of highly educated mothers were significantly higher in all four areas of development than those of mothers of low education.

The second and more interesting finding was that where there was a comparable group in terms of education and numbers, i.e. the middle education group, it was then found that the mean DQ of North African babies compared to European babies was higher in all areas of development and significantly so within the motor and adaptive areas. Unfortunately no comparison could be made in the higher or lower education groups between European and North African babies due to lack of numbers. The meaning of middle education has to be interpreted cautiously as due to cultural differences: a girl from a patriarchal North African family may have achieved higher education in another culture.

The effect on DQ of years of schooling of the mother was studied rather than socioeconomic level. It was felt that this gave a more accurate indication of both the mothers' $D Q$ and her environmental background. Further, the socioeconomic groupings of other countries are not applicable to Israel. It was also thought important to consider the DQ for each of the four areas of development rather than to rely upon a total or

TABLE III

Means and SDs of the four areas of development by ethnic groups of mother in medium education group

\begin{tabular}{|c|c|c|c|c|c|c|c|c|c|}
\hline & \multirow{2}{*}{ No. } & \multicolumn{2}{|c|}{ Motor } & \multicolumn{2}{|c|}{ Adaptive } & \multicolumn{2}{|c|}{ Language } & \multicolumn{2}{|c|}{ Social } \\
\hline & & Mean DQ & SD & Mean DQ & SD & Mean DQ & SD & Mean DQ & SD \\
\hline $\begin{array}{l}\text { North African } \\
\text { European } \\
\text { Asian } \\
\text { Israeli }\end{array}$ & $\begin{array}{l}25 \\
10 \\
10 \\
27\end{array}$ & $\begin{array}{r}110 \cdot 6 \\
98 \cdot 4 \\
105 \cdot 4 \\
104 \cdot 6\end{array}$ & $\begin{array}{c}12 \cdot 2 \\
16 \cdot 7 \\
7 \cdot 08 \\
14 \cdot 6\end{array}$ & $\begin{array}{r}105 \cdot 6 \\
96 \cdot 7 \\
99 \cdot 4 \\
101 \cdot 1\end{array}$ & $\begin{array}{r}10 \cdot 0 \\
16 \cdot 3 \\
9 \cdot 0 \\
11 \cdot 3\end{array}$ & $\begin{array}{l}110 \cdot 7 \\
104 \cdot 0 \\
103 \cdot 9 \\
107 \cdot 7\end{array}$ & $\begin{array}{l}13 \cdot 9 \\
14 \cdot 2 \\
12 \cdot 8 \\
12 \cdot 6\end{array}$ & $\begin{array}{l}110 \cdot 6 \\
101 \cdot 4 \\
108 \cdot 5 \\
105 \cdot 8\end{array}$ & $\begin{array}{l}13 \\
16 \\
23 \\
12\end{array}$ \\
\hline
\end{tabular}

TABLE IV

Differences in means of the four areas of development for babies of North African and European origin

\begin{tabular}{|c|c|c|c|c|}
\hline & Medn DQ of North African & Mean DQ of European & Difference & $\mathbf{P}$ \\
\hline $\begin{array}{l}\text { Motor } \\
\text { Adaptive } \\
\text { Language } \\
\text { Social }\end{array}$ & $\begin{array}{l}111 \cdot 6 \\
105 \cdot 6 \\
110 \cdot 7 \\
110 \cdot 6\end{array}$ & $\begin{array}{l}98 \cdot 4 \\
96 \cdot 7 \\
104 \\
101 \cdot 4\end{array}$ & $\begin{array}{r}12 \cdot 2 \\
8 \cdot 9 \\
6 \cdot 7 \\
9 \cdot 2\end{array}$ & $\begin{array}{l}<0.05 \\
<0.05 \\
<0.1 \\
<0.1\end{array}$ \\
\hline
\end{tabular}




\section{Effect of maternal education and ethnic background on infant development}

composite figure, and thus to avoid the problem of weighting of the score by one particular area of development. Special care in this direction is necessary with the Gesell and Amatruda (1947) test, of which the Brunet and Lezine is a derivative, in the light of criticism of it on the grounds of a motor bias.

There are arguments over the value of $D Q$ tests. That they can show areas of developmental retardation at a specific early age period is clear, but it is disputed whether they are of any value in predicting future $D Q$, and if so, how early. Nancy Bayley (1955) concluded in her study that there was no correlation. But her study was criticized on the grounds of being confined to institutionalized children. When DQ studies were performed with broader groupings (Illingworth, 1960; Simon and Bass, 1956; Knobloch and Pasamanick, 1963), a correlation was traceable between $\mathrm{DQ}$ scores below one year and later DQ and IQ measurements. In this particular study it was seen that the infants of the mothers of high education scored significantly higher in all four areas of development but least in the motor area. This suggests that maternal education exercises more influence in these fields. Even though the infants showed a higher total level of development, those areas more exposed to stimulus were even higher. This finding agrees with those of others who claimed that the best predictor of a child's future IQ was that of his mother (Honzick, 1957; Burt, 1958).

The other variable of interest in this study was the effect of ethnic group on the DQ of the child, (Tables III and IV). What we see is that the babies of North African origin score higher in all areas of development than the European, and particularly in the area of motor development. The advancement in motor development may be a reflection of physical development, and it was found in a study by Epstein (1963) of babies in the same area of Jerusalem that the babies of North African origin started with a higher birthweight than those of other ethnic groups. The fact that the babies of North African origin were more developed fits the findings of Geber (1956) in her studies of Ugandan babies. The problem of why there are ethnic group differences is a complex one, but is one that is broadly divided into genetic and environmental variables. The fact that in this study the North African babies scored highest in the area that was least affected by stimulus, i.e. the motor, hints at the possible importance of maternal stimulus on future intellectual development. It would be of interest to follow-up the North African babies to see if they maintain their developmental advance, or whether there is a falling off as in weight-as found by Epstein (1963). That there may be a possibility of falling off is suggested by studies of both Knobloch and Pasamanick (1963) on white and Negro children and Geber (1956) on Ugandan babies of poor and middle class families. The fact that Geber found differences related to socioeconomic background in the same ethnic group supports the importance of environment

This study and others (Illingworth, 1960) indicate the value of $D Q$ measurements in terms of broad groups rather than individuals, and the advantage, therefore is in planning services or programmes of stimulation or intervention in which the special needs of a specific group is open to full study and, hopefully, to effective resolution.

I thank Professor Alex Russell of the Department of Paediatrics for his helpful criticism of the material; and also Drs. Z. Shamir for tutorship, M. Gitlin, D. Flug, and B. Gampel for! assistance in carrying out the study; and finally the Public Health Nurses of the Kiryat Yovel area for their patience and assistance in busy clinics.

\section{REFERENCES}

Bayley, N. (1955). On the growth of intelligence. American Psychologist, 10, 805.

Brunet, O., and Lezine, I. (1951). Le Développement Psychologique de l'Enfant. Presses Universitaire de France, Paris.

Burt, C. (1958). The inheritance of mental ability. American Psychologist, 13, 1.

Darwin, C. (1877). A Biographical Sketch of an Infant Mind, vol. 2, p. 285.

Epstein, L. (1963). An epidemiological study of infant growth in different groups of babies in the Western region of Jerusalem. M.P.H. Thesis, Hadassah Medical School.

Geber, M. (1956). Development Psycho-moteur de L'enfant Africain, vol. 6, no. 1, p. 17 . International Children's Centre.

Geber, M. (1958). L'Enfant Africain Occidentalise et de Niveau Social Superieur, vol. 8, no. 9, p. 517. International Children's Centre.

Gesell, A., and Amatruda, C. S. (1947). Developmental Diagnosis. 2nd ed. Hoeber, New York.

Honzick, M. P. (1957). Developmental studies of parent-child resemblance in intelligence. Child Development, 28, 215.

Illingworth, R. S. (1960). The predictive value of developmental assessment. The Development of the Infant and Young Child, 3rd ed., p. 5. Livingstone, Edinburgh and London.

Knobloch, H., and Pasamanick, B. (1963). Predicting intellectual potential in infancy. American fournal of Diseases of Children, $106,43$.

Simon, A. J., and Bass, L. G. (1956). Towards validation of infant testing. American fournal of Orthopsychiatry, 26, 340.

Correspondence to Dr. T. Ivanans, Department of Paediatrics, Hadassah Medical Centre, Hebrew University, Jerusalem, Israel. 